\title{
Fate of the thiomalate part after intramuscular administration of aurothiomalate in rheumatoid arthritis
}

\author{
E. JELLUM ANDE. MUNTHE \\ From the Institute of Clinical Biochemistry, Rikshospitalet, and Oslo City Department of Rheumatology, \\ Diakonhjemmets Hospital, Oslo, Norway
}

SUMMARY The excretory fate and plasma level of thiomalate were studied after intramuscular administration of auro- ${ }^{14} \mathrm{C}$-thiomalate to 3 patients with rheumatoid arthritis. The gold and the thiomalate parts separated in vivo, and the free thiomalate was excreted in the urine, rapidly at first and then slowly. After one day about $60 \%$ of the ${ }^{14} \mathrm{C}$-label had been recovered in the urine. The plasma level also declined rapidly. The results are in complete agreement with those previously described in animal experiments.

Recently we showed, using double isotope-labelled aurothiomalate $\left({ }^{195} \mathrm{Au}-{ }^{14} \mathrm{C}\right.$-thiomalate) that the gold and the thiomalate separate in vivo, resulting in protein-bound gold and release of free thiomalate. ${ }^{1}$ About half of this thiol is excreted in the urine during the first day, and the remaining half is bound to tissue membranes and cells.

These experiments were all carried out on animals (mice and rats). In view of the biological effects of thiomalate ${ }^{2}$ and its possible antirheumatic activity it would be desirable also to study in detail the fate of the thiomalate part after intramuscular administration of aurothiomalate to man. The results of such a study are presented in this report.

\section{Materials and methods}

Highly purified ${ }^{14} \mathrm{C}$-labelled sodium aurothiomalate $\left(\mathrm{Na}_{2}\right.$ Au $\left[2,3-{ }^{-14} \mathrm{C}\right.$ - $]$ thiomalate $)$ was kindly synthesised for us by May and Baker, Dagenham, London. The purity of this compound as checked by thin-layer chromatography was over $99 \%$. Before injection the radiolabelled compound was dissolved in distilled water, the $\mathrm{pH}$ was adjusted to $7 \cdot 4$, and the solution was filtered through a $0.22 \mu \mathrm{m}$ Millipore filter into a sterile flask.

The volunteer patients were 2 females, 51 and 26 years of age, and a 41-year-old man. All of them had been on regular treatment with Myocrisin for the past months because of classical, rheumatoid-factor positive rheumatoid arthritis $(50 \mathrm{mg}$ of aurothiomalate

Accepted for publication 3 August 1981.

Correspondence to Dr E. Jellum, Institute of Clinical Biochemistry, Rikshospitalet, Oslo 1, Norway. injected once every week). In addition the patients used acetylsalicylic acid or naproxene; the man was also on treatment with corticosteroids $(2.5 \mathrm{mg}$ prednisolone per day).

The patients were given an intramuscular injection of a weighed and exact amount of the ${ }^{14} \mathrm{C}$-labelled aurothiomalate (about $30 \mathrm{mg}$ of substance corresponding to about $23 \mu \mathrm{Ci}$ of radioactivity). Urine and blood samples were collected at intervals, and ${ }^{14} \mathrm{C}$ activity was counted in a Packard Tri-Carb liquid scintillation spectrometer using Packard Instagel II scintillator cocktail. All results were corrected for quenching. The identity of the labelled compounds which were present in the urine and serum was confirmed by thin-layer chromatography as previously described. ${ }^{3}$

\section{Results}

The excretion curves (Fig. 1) show that the ${ }^{14} \mathrm{C}$-label of the aurothiomalate is excreted at a rapid rate initially and then very slowly. After 22 hours about $62 \%$ of the radioactivity had been recovered in the urine. Thin-layer chromatography showed that free thiomalate and thiomalate disulphide accounted for nearly all the ${ }^{14} \mathrm{C}$-activity in the urine of all 3 patients.

Fig. 2 shows the amount of ${ }^{14} \mathrm{C}$-label present in blood plasma at different times after injections. The label is rapidly eliminated, and after one day as little as $0.3 \%$ of the ${ }^{14} \mathrm{C}$-activity remains in the plasma. Since the curves reflect a number of events, including absorption from the injection site in the muscle, exchange of aurothiomalate with protein-SH groups, redistribution to various organs, and elimination of 


\section{Jellum, Munthe}

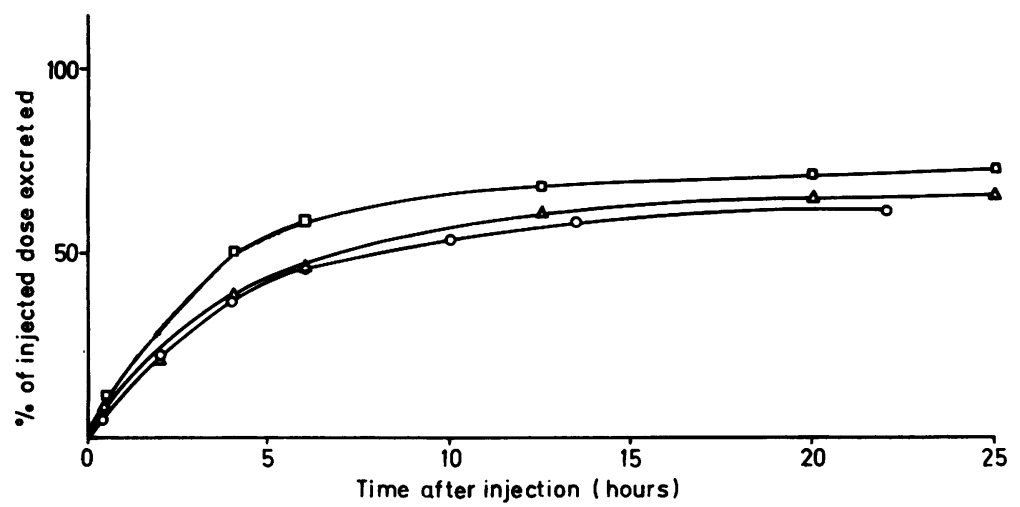

Fig. 1 Urinary excretion of ${ }^{14} \mathrm{C}$-label after intramuscular injection of auro- ${ }^{14} \mathrm{C}$-thiomalate to 3 patients with rheumatoid arthritis. Circles=patient 1. Squares $=$ patient 2 . Triangles $=$ patient 3 .

free thiomalate by the kidneys, all in non steady state, no attempts have been made to calculate kinetic constants.

\section{Discussion}

Analysis of the urine samples collected after injection of the auro- ${ }^{14} \mathrm{C}$-thiomalate clearly shows that in man as in the animal experiments the gold and the thiomalate moieties separate in vivo, resulting in an initial rapid excretion of free thiomalate in the urine. Six to twelve hours after the intramuscular injection of the gold complex, the elimination of the ${ }^{14} \mathrm{C}$-label in the urine is very slow, and at the same time the amount of label circulating in plasma is very low. These results closely parallel those found in the case of mice ${ }^{1}$ and reflect that a considerable portion (about $40 \%$ of the injected dose) of the thiomalate has become bound to tissue membranes and cells. In view of these results and the recently demonstrated effects of thiomalate in in-vitro systems ${ }^{2}$ it is probable that part of the drug action of Myocrisin in man is due to the thiomalate. Preliminary clinical trial indicates that thiomalate may have an antirheumatic effect. ${ }^{4}$

The authors thank Mrs Gro Guldal for expert technical assistance. Norsk Hydro's Fund for Rheumatism Research supported our work financially. We also acknowledge support from Norske Kvinners Sanitetsforenings Forskningsford and Det Norske Revmatismeråd. We are grateful to May and Baker Ltd, England, for supplying us with radiolabelled Myocrisin.

\section{References}

1 Jellum E, Munthe E, Guldal G, Aaseth J. Fate of the gold and the thiomalate part after intramuscular administration of aurothiomalate to mice. Ann Rheum Dis 1980; 39: 155-8.

${ }^{2}$ Arrigoni-Martelli E, Bramm E, Binderup L. D-penicillamine-like activity of thiols. Eur J Rheumatol Inflamm 1978; 1: 197-203.

3 Jellum E, Munthe E, Guldal G, Aaseth J. Gold and thiol compounds in the treatment of rheumatoid arthritis: excretory fate and tissue distribution of thiomalate in relation to gold after administration of Myocrisin (aurothiomalate). Scand J Rheumatol 1979; suppl 28: 28-36.

4 Munthe E, Jellum E. Tolerance and effectiveness of sodiumthiomalate without gold in rheumatoid arthritis. In: Friman C, ed. XVIII Nordic Congress of Rheumatology, Helsinki June 1-4, Abstracts. Scand J Rheumatol 1980; suppl 33: abstract 42: 21.
Fig. 2 Plasma level of ${ }^{14} \mathrm{C}$-label after intramuscular injection of auro- ${ }^{14} \mathrm{C}$-thiomalate to 3 patients with rheumatoid arthritis. Patients as above.

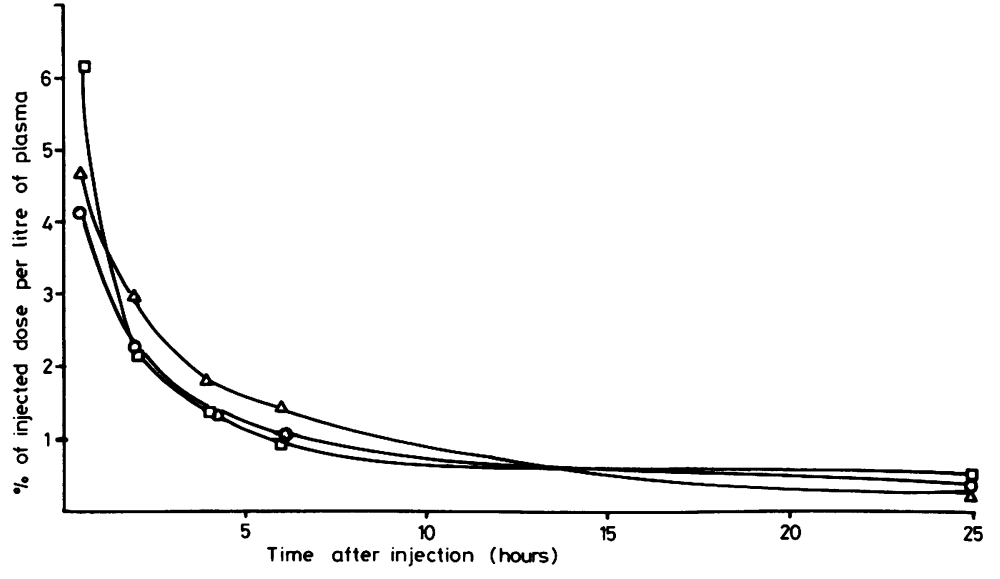

